\title{
Driving Load Estimation with the Use of an Estimated Turbine Torque*
}

\author{
Deok-Ho KIM* ${ }^{* *}$ Keum-Shik HONG ${ }^{* * *}$ and Kyongsu YI ${ }^{* * * *}$
}

\begin{abstract}
In this paper, a vehicle driving load estimation scheme in the form of a linear state observer is presented. The signals used in the observer are the transmission output speed and driven wheel speed, which are readily available in any vehicle equipped with an automatic transmission. Because the observer requires the turbine torque as input, the turbine torque itself has been estimated using a neural network. The proposed observer has been evaluated using a vehicle simulator in various driving situations considering transmission oil temperature variations, engine power losses, and variation of load conditions. A nonlinear vehicle powertrain model has been used in the development of the vehicle simulator. The effectiveness of the proposed scheme has been tested through experiments.
\end{abstract}

Key Words: Vehicle Driving Load, Powetrain, Observer, Torque Estimation, Neural Networks

\section{Introduction}

Recently, various advanced vehicle control systems such as longitudinal control, access control, climate control, and others are being developed in the automobile industry. The most notable one among them is vehicle longitudinal control. Two difficulties in realizing a robust longitudinal control ${ }^{(1)-(4)}$, which provides both improved safety and driving comfort, are seen from two aspects: The vehicle dynamics is highly nonlinear and a number of core signals are not easily obtained.

In the longitudinal motion control, the ignorance of the driving resistance load (driving load in short) is known to be the most influential factor limiting its control performance. The importance of knowing the driving load has been recognized in many related works: an intelligent cruise control system ${ }^{(1),(3),(5)}$, a collision warning and

* Received 11th March, 2004 (No. 04-5032)

** Microsystem Research Center, Korea Institute of Science and Technology, P. O. Box 131, Cheongryang, Seoul 130650 , Korea.

E-mail: kim-dh@kist.re.kr

*** School of Mechanical Engineering, Pusan National University, 30 Jangjeon-dong, Gumjeong-gu, Busan 609-735, Korea. (corresponding author)

E-mail: kshong@pusan.ac.kr

**** School of Mechanical and Aerospace Engineering, Seoul National University, Kwanak-ku, Shillim-dong, Seoul, Korea. E-mail: kyi@snu.ac.kr avoidance system ${ }^{(4)}$, a longitudinal vehicle platoon control $^{(2)}$, and a powertrain control system ${ }^{(6)-(10)}$, and others.

The driving load of a vehicle in motion is defined as the sum of the rolling resistance, aerodynamic drags, and road grade resistance ${ }^{(11)}$, in which the road grade resistance is known to be the most dominant one ${ }^{(12)}$. Most previous works in the literature have treated the driving load as an external disturbance ${ }^{(1),(6),(10),(13),(14)}$. Therefore, the performance of a longitudinal motion control depended heavily on how well the robustness of the designed controller has been assured over the driving load.

Measuring the driving load is not impossible but is costly. Particularly, adding additional sensors works against the trend of lowering the total cost of a mass production car. Hence, if the deriving load can be estimated somehow rather than measuring it, would be a good alternative in improving the longitudinal motion control. Ohnishi et al. ${ }^{(11)}$ proposed an estimation method of the road slope using a simple kinetic method for the purpose of avoiding shift changes in up-hills or down-hills. Kim et al. ${ }^{(15)}$ proposed an observer-based driving load estimation algorithm that can be implemented with inexpensive RPM sensors that are already being used. In the work of Ohnishi et al. ${ }^{(11)}$, the road slope is estimated using the equation of motion that involves the mass of the vehicle, where they assumed the mass being constant. However, the mass normally changes depending on the number of passengers and load. On the other hand, in the feedback observer method using speed sensors, the mass change does not effect the 
speed change directly. Therefore, the advantage of using an observer scheme is that the mass change can be allowed and moreover the effects of sensor noises, disturbances acting on the vehicle, and model uncertainties can be reduced by feedback signals.

In this paper, a new driving load estimation of turbine torque using neural networks has been incorporated in the observer-based estimation algorithm to achieve a better performance over variations in the automotive power transmissions process. The performance of the developed estimation algorithm has been evaluated using a nonlinear full vehicle simulation model in two different cases; in the presence of modeling error and under the uncertain load environment. The proposed method can be utilized for the development of an advanced longitudinal control system.

The contributions of this paper are: A driving load estimation method in the form of an observer design is firstly proposed. Secondly, the proposed observer is combined with a turbine torque estimation scheme using neural networks. Therefore, the robustness of the algorithm upon variations of the vehicle speed, oil temperature, throttle angle, etc. has been greatly improved.

The paper is structured as follows: In section 2, the dynamic models for powertrain components are described. In section 3, the observer design for the driving resistance load estimation is introduced. In section 4 , in order to estimate the unknown input, i.e. the turbine torque in the proposed observer design, a new torque estimation technique using neural networks is described. In section 5, the performance of the proposed estimation algorithm is simulated via a nonlinear full vehicle model. In section 6, experimental results in the dynamometer are given. Conclusions are given in section 7.

\section{Vehicle Powertrain Model}

Figure 1 is a schematic of the vehicle powertrain system depicting driving resistances. The powertrain system consists of an engine, a torque converter, an automatic transmission, a driveline, and the driving resistances include wind drags, road slope, and rolling resistance. The powertrain system delivers the engine torque to the driving wheels through a serious of components in the system, in which the automatic transmission changes gear ratios

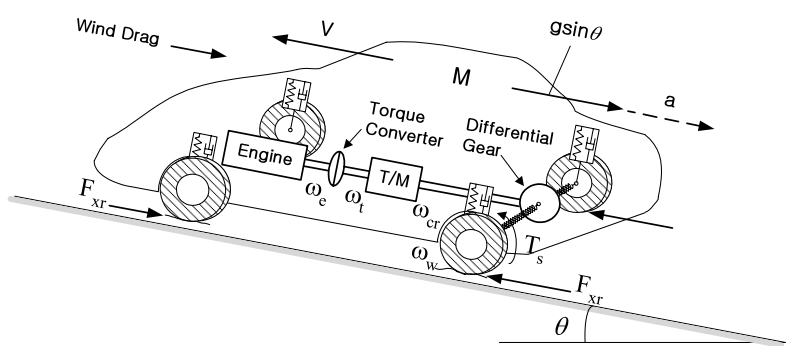

Fig. 1 The considered vehicle powertrain system with driving resistances upon various torque loads by engaging and disengaging the hydraulically driven clutches. Even though the modeling of powertrain components is not the issue in this paper, but for the completeness of this paper, a number of mathematical models needed are briefly outlined in this section.

\subsection{Engine}

The engine is a complex and highly nonlinear subsystem. The following equation representing the engine dynamics is adopted:

$$
I_{e} \dot{\omega}_{e}=T_{e}\left(\omega_{e}, \alpha\right)-T_{p},
$$

where $I_{e}$ denotes the engine inertia $\left(\mathrm{kg} \mathrm{m}^{2}\right), \omega_{e}$ is the engine speed (rpm), $\alpha$ is the throttle angle $(\%), T_{p}$ is the torque converter pump torque ( $\mathrm{Nm})$, and $T_{e}$ is the engine torque that is a nonlinear function of $\omega_{e}$ and $\alpha$.

\subsection{Torque converter}

The torque converter consists of a pump (input), a turbine (output), and a stator (reaction member). The pump is directly connected to the engine and therefore turns at the same speed of engine. Torque is transmitted to the turbine through the oil flow induced by the pump. The steadystate pump torque $T_{p}$ and turbine torque $T_{t}$ of a typical torque converter are given as follows:

$$
\begin{aligned}
& T_{p}=C_{p}\left(\omega_{e}, \omega_{t}\right) \omega_{e}^{2}, \\
& T_{t}=T_{r}\left(\omega_{e}, \omega_{t}\right) T_{p},
\end{aligned}
$$

where $C_{p}$ is the capacity factor and $T_{r}$ is the torque ratio. $C_{p}$ and $T_{r}$ are nonlinear functions of the ratio of engine and turbine rotational speeds, respectively, which are normally provided by the manufacturer as a look-up table.

\subsection{Automatic transmission}

An automatic transmission consists of several planetary gears and associated clutches and bands. In this paper, a two-state transmission model (i.e., $\omega_{t}$ and $\omega_{c r}$ ) is adopted $^{(16),(17)}$.

The state equation in first gear is given by

$$
I_{t 1} \dot{\omega}_{t}=T_{t}-R_{1} R_{d} T_{s},
$$

where $I_{t 1}=I_{t}+I_{s i}+R_{1}^{2} I_{c r}+\frac{R_{1}^{2}}{R_{2}^{2}} I_{c i}, \omega_{t}$ is the turbine speed, $R_{1}$ is the first gear speed reduction ratio, $R_{2}$ is the second gear speed reduction ratio, $R_{d}$ is the final drive speed reduction ratio, $T_{s}$ is the axle torque (both sides combined), $I_{t}$ is the converter turbine and chain inertia, $I_{s i}$ is the input sun inertia, $I_{c r}$ is the reaction carrier inertia, and $I_{c i}$ is the input carrier inertia.

When the vehicle reaches a shift speed, a hydraulic control circuit applies the second clutch. This initiates the starting of $1-2$ upshift. The state equation during the torque phase is modeled as

$$
I_{t} \dot{\omega}_{t}=T_{t}-R_{1} R_{d} T_{s}-\left(1+\frac{R_{2}}{R_{1}}\right) T_{c 2},
$$

where $T_{c 2}$ is the torque on the second clutch, i.e., oncoming clutch. During the inertia phase, the state equations for the converter turbine and the carrier become 


$$
\begin{aligned}
& I_{t} \dot{\omega}_{t}=T_{t}-T_{c 2}, \\
& I_{c r 12} \dot{\omega}_{c r}=\frac{T_{c 2}}{R_{2}}-R_{d} T_{s},
\end{aligned}
$$

where $I_{c r 12}=I_{c r}+\frac{I_{s i}}{R_{1}^{2}}+\frac{I_{c i}}{R_{2}^{2}}$.

When the slip speed of the second clutch $\left(\Delta \omega_{c 2}\right)$ reaches zero, the second clutch locks up. Hence, the state equation in second gear is modeled as

$$
I_{t 2} \dot{\omega}_{t}=T_{t}-R_{2} R_{d} T_{s}
$$

where $I_{t 2}=I_{t}+I_{c i}+R_{2}^{2} I_{c r}+\frac{R_{2}^{2}}{R_{1}^{2}} I_{s i}$.

\subsection{Clutch torque model}

The clutch torque $T_{c 2}$ is given as a static function of the clutch hydraulic pressure, clutch geometry, plate friction characteristics, and the clutch slip speed. For calculating the clutch torque, the following equation is used:

$$
T_{c 2}=A_{c 2} \cdot \delta \cdot P_{c 2} \cdot \operatorname{sgn}\left(\Delta \omega_{c 2}\right),
$$

where $A_{c 2}$ denotes the total clutch area of the gear times the effective radius; $\delta=\delta_{s}+\delta_{d}\left|\Delta \omega_{c i}\right|$, where $\delta_{s}, \delta_{d}>0, P_{c 2}$ is the hydraulic pressure applied to the clutch, and $\Delta \omega_{c 2}=$ $\omega_{t}-\frac{\omega_{c r}}{R_{2}}$.

The pressures of clutches and brakes are controlled by electromagnetic valves. Since the dynamics of hydraulic parts is nonlinear and high-order, it is not easy to model the dynamics in detail for the analysis of shift transients. Thus, a model based on the steady-state characteristics of the hydraulic parts from a look-up table is widely used for a shift control.

\subsection{Driveline model}

The angular velocity of the final drive output shaft is the input to the axle shaft. The axle shaft is modeled as a torsional spring as

$$
\dot{T}_{s}=K_{s}\left(R_{d} \omega_{c r}-\omega_{w}\right),
$$

where $T_{s}$ is the shaft torque of the output axle, $K_{s}$ is the torsional stiffness and $\omega_{w}$ is the wheel speed. The rotational dynamics of the driving wheel is given by

$$
I_{w} \dot{\omega}_{w}=T_{s}-T_{L},
$$

where $I_{w}$ is the equivalent vehicle inertia and $T_{L}$ is the driving load.

The driving load is modeled as the sum of the rolling resistance, aerodynamic drags, and road grade resistance as follows:

$$
T_{L}=r_{t}\left(C_{a} V^{2}+M g \sin \theta+\mu_{r} M g\right),
$$

where $r_{t}$ is the tire radius, $C_{a}$ is the aerodynamic drag coefficient, $V$ is the vehicle speed, $M$ is the mass of the vehicle, $g$ is the gravitational acceleration, $\theta$ is the road grade in degree, and $\mu_{r}$ is the rolling resistance coefficient.

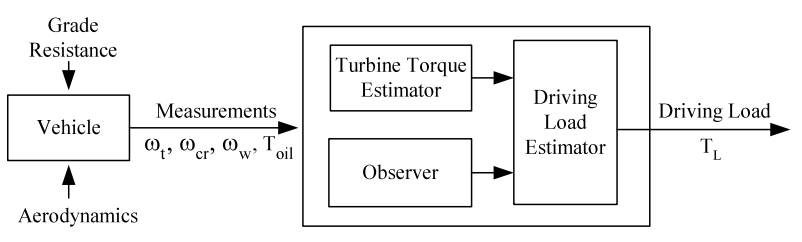

Fig. 2 Estimation scheme of the driving load

\section{Observer Design}

Figure 2 shows an estimation scheme of the driving load, $T_{L}$, in the form of an observer design. The estimation algorithm can be divided into two parts: linear observer design with rpm measurements and unknown input torque estimation $\left(\omega_{c r}\right.$ and $\omega_{w}$ for linear observer and $\omega_{t}$ and $T_{\text {oil }}$ for torque estimation, see Fig. 2). The speed signals, after reducing noises with the use of Kalman filter, are supplied to the turbine torque estimator as an input and the driving load observer as a measured signal. For a driving load observer design, the models in section 2 are utilized. These models have been used in the areas of vehicle longitudinal control $^{(18)}$ and observer design ${ }^{(19),(20)}$ and are sufficient to capture the dynamics of a given powertrain system.

First, the following assumptions are made: 1) the road surface condition is the same throughout all tires. 2) The no-slip assumption has been incorporated, because the wheel slip is quite small at a low level of acceleration. 3) The brake torque is neglected during a throttle operation.

Now, the differential equation for the transmission carrier speed is

$$
\dot{\omega}_{c r}=\frac{1}{I_{c r, i}}\left(\frac{T_{t}}{R_{i}}-R_{d} T_{s}\right)
$$

where $I_{c r, i}$ is the carrier inertia at the $i$-th gear ratio, and $R_{i}$ and $R_{d}$ are the $i$-th gear ratio and the final drive gear ratio, respectively. The equation of motion for the wheel is written as follows:

$$
\dot{\omega}_{w}=\frac{1}{I_{v}}\left(T_{s}-T_{L}\right) .
$$

The equation for the axle shaft torque dynamics is

$$
\dot{T}_{s}=K_{s}\left(R_{d} \omega_{c r}-\omega_{w}\right) .
$$

Note that in (14), the driving load $T_{L}$ is unknown and inaccessible. Hence, for estimating it, the driving load is considered as a 4-th state variable, and estimated in the form of an observer.

Since the variation of the vehicle driving load, $T_{L}$, is slow compared to the observer dynamics, the O-observer ${ }^{(21)}$ is used in order to simplify the observer design, assuming that

$$
\dot{T}_{L}=0 \text {. }
$$

Now, gathering all equations, the model for an observer design is summarized as follows: 


$$
\begin{aligned}
& \dot{\omega}_{c r}=\frac{1}{I_{c r, i}}\left(\frac{T_{t}}{R_{i}}-R_{d} T_{s}\right), \\
& \dot{\omega}_{w}=\frac{1}{I_{v}}\left(T_{s}-T_{L}\right), \\
& \dot{T}_{s}=K_{s}\left(R_{d} \omega_{c r}-\omega_{w}\right), \\
& \dot{T}_{L}=0,
\end{aligned}
$$

where the state vector is defined as follows:

$$
x=\left[\begin{array}{llll}
\omega_{c r} & \omega_{w} & T_{S} & T_{L}
\end{array}\right]^{T} .
$$

Let the input be $u=T_{t}$ (the turbine torque). Let the transmission output speed and driven wheel speed be measured outputs, i.e., $y=\left[\begin{array}{ll}\omega_{c r} & \omega_{w}\end{array}\right]^{T}$. Then, the state-space model for an observer design is set as follows:

$$
\begin{aligned}
& \dot{x}=A x+B u, \quad u=T_{t}, \\
& y=C x+n,
\end{aligned}
$$

where

$$
\begin{aligned}
A & =\left[\begin{array}{cccc}
0 & 0 & -\frac{R_{d}}{I_{c r, i}} & 0 \\
0 & 0 & \frac{1}{I_{v}} & -\frac{1}{I_{v}} \\
K_{S} R_{d} & -K_{S} & 0 & 0 \\
0 & 0 & 0 & 0
\end{array}\right], \quad B=\left[\begin{array}{c}
\frac{1}{I_{c r, i} R_{i}} \\
0 \\
0 \\
0
\end{array}\right], \\
C & =\left[\begin{array}{llll}
1 & 0 & 0 & 0 \\
0 & 1 & 0 & 0
\end{array}\right] .
\end{aligned}
$$

Note that $\omega_{c r}$ and $\omega_{w}$ are easily measurable using inexpensive rpm sensors currently in use on the vehicles equipped with an anti-skid braking system.

The following observer can be used for the estimation of the driving load:

$$
\begin{aligned}
& \dot{\hat{x}}=A \hat{x}+B \hat{u}+L[y-C \hat{x}], \\
& y=C x+n,
\end{aligned}
$$

where $\hat{u}$ is the estimated input. However, another problem left is that the input to the observer, the turbine torque $T_{t}$, is not known yet and is inaccessible either. So, the turbine torque estimation is now discussed in the next section.

\section{Turbine Torque Estimation}

The turbine torque is an unknown input to the observer proposed. The accuracy in estimating the driving load depends absolutely on the performance of estimating the unknown torque.

\subsection{Regression fitting method}

In general, the turbine torque model using two nonlinear characteristic functions of the torque converter, which is provided by the manufacturer as a look-up table, has been widely used in vehicle control areas. The turbine torque, which is an unknown input to the observer, has been estimated using two nonlinear characteristic functions of the torque converter, as shown in Fig. 3. In this paper, the turbine torque model has been obtained from a regression fit of experimental data, given in (20).

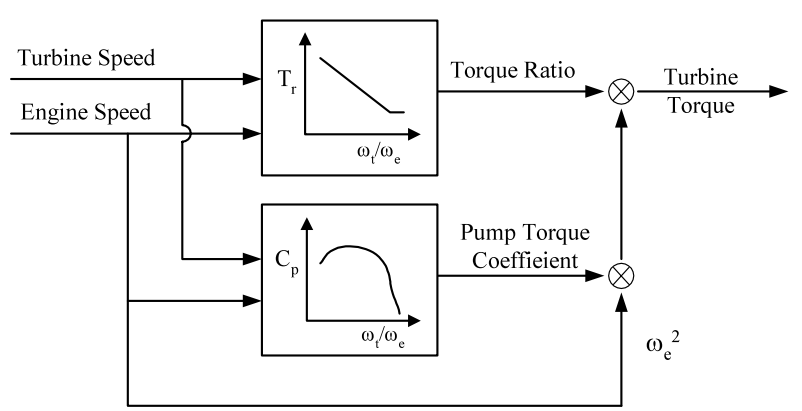

Fig. 3 Turbine torque estimation using two nonlinear characteristic functions of the torque converter

$$
\begin{aligned}
& T_{p}=C_{p}(r) \omega_{e}^{2}, \\
& T_{t}=T_{r}(r) T_{p},
\end{aligned}
$$

where $r=\frac{\omega_{t}}{\omega_{e}}$,

$$
\begin{aligned}
& T_{r}(r)=\left\{\begin{array}{cc}
-1.412 r+2.2 & r<0.85 \\
1 & r \geq 0.85
\end{array}\right\}, \\
& C_{p}(r)=10^{-3} \times\left(-1.695 r^{2}+0.2946 r+1.874\right) .
\end{aligned}
$$

\section{2 Neural network modeling}

The input torque to an automatic transmission, which is generated from the engine, is delivered and amplified by a torque converter. In particular, the turbine torque is transferred to the automatic transmission as a result of the oil-induced flow in the torque converter, and oil properties vary upon the variation of oil temperature. However, there are several uncertainties in the input torque from engine to automatic transmission. For example, the torque converter characteristics depend on the temperature of internally induced oil. Figure 4 shows the effect of oil temperature on the turbine torque. Results from experiments indicate that the torque loss caused by the drag torque in the torque converter due to variations of oil temperature, from $30^{\circ} \mathrm{C}$ to $80^{\circ} \mathrm{C}$, is quite significant. Eight to twentyfive percent variations of the turbine torque has been observed for the above oil temperature variation. Hence, the torque converter characteristics is considerably affected by the temperature of internally induced oil and a more accurate estimation of the turbine torque can be obtained by considering the oil temperature variation.

The magnitude of this torque is mainly determined by a throttle operation and the torque converter characteristics. The loss in torque production due to the variation in oil temperature should be considered in vehicle control applications. In this paper, a new modeling approach using neural networks has been introduced, so that a more accurate turbine torque compensation can be obtained. The structure of the Feedforward Neural Network (FNN) model used for a turbine torque estimation is shown in Fig. 5. The input pattern of the FNN model is composed of engine speed, turbine speed, and oil temperature in the torque converter. The output of the model is the driving 
torque part of the turbine torque given in (21).

$$
T_{t}=\left.T_{t}\right|_{\text {Drive }}+\left.T_{t}\right|_{\text {Loss }}
$$

where $\left.T_{t}\right|_{\text {Drive }}$ is the actual driving torque part in the torque converter and $\left.T_{t}\right|_{\text {Loss }}$ is the drag loss in the torque converter depending on oil temperature.

In this paper, the used activation function in the hidden layers in Fig. 5 is a hyper-tangent sigmoid function and that in the output layer is a pure linear sigmoid func-

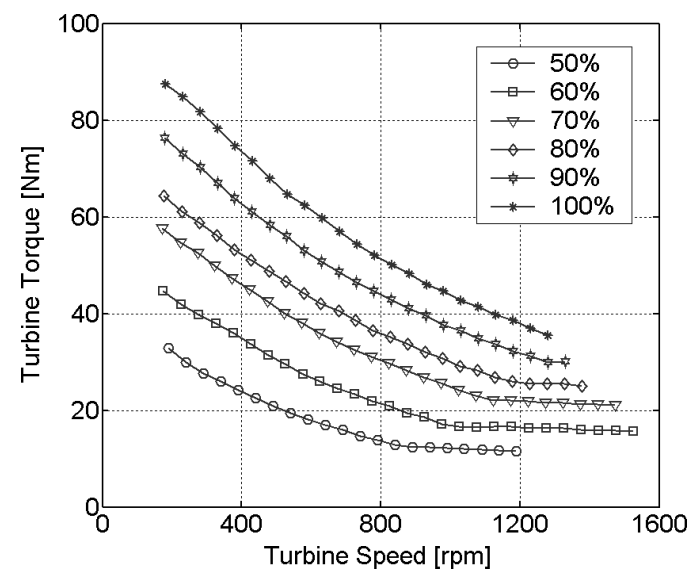

(a) At oil temperature $30^{\circ} \mathrm{C}$

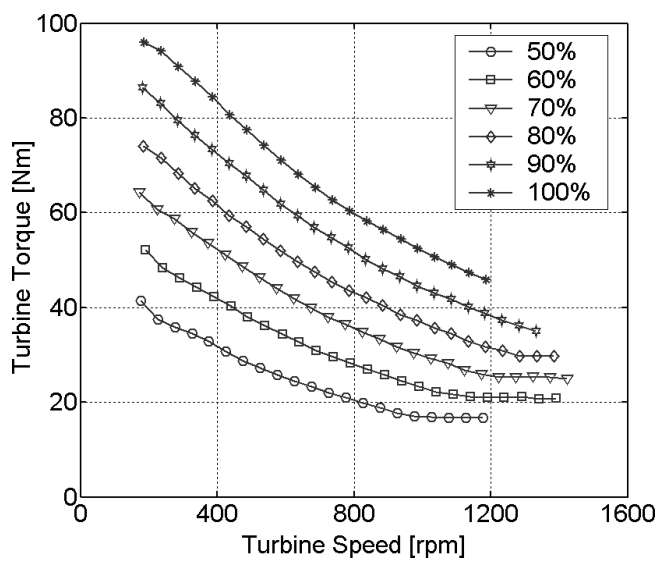

(b) At oil temperature $80^{\circ} \mathrm{C}$

Fig. 4 Variations in turbine torque affected by torque converter oil temperature according to various driving torques from a torque-controlled $\mathrm{AC}$ motor

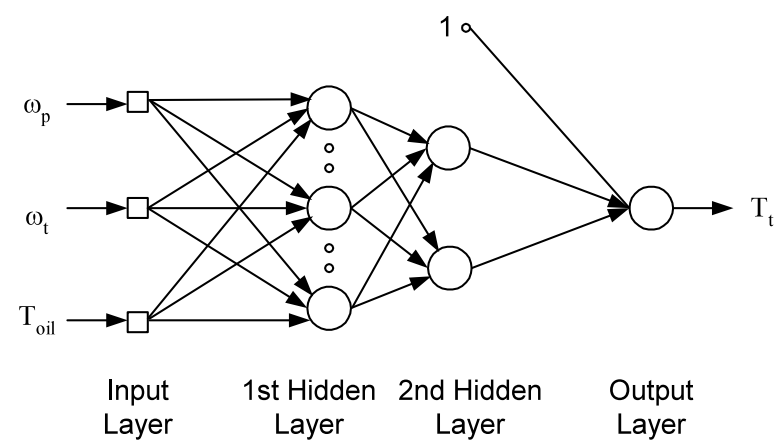

Fig. 5 Neural network architecture for a turbine torque estimation tion $^{(22)}$. The number of neurons in the first and second hidden layers are eight and two, respectively. The used learning algorithm is the Gauss-Newton method. The input and output variables are normalized to the values between -1 and 1 by subtracting their averages. For learning, total 72 data set were used. The mean squares error of a well-trained neural network model was 0.2692 , which represents a relative error of $3.54 \%$.

By introducing oil temperature as another variable representing better torque converter characteristics, the torque variation due to the change in oil properties can be compensated. Even when torque converter characteristics change or the performance of the engine degrades, accurate torque information can be obtained using three measured variables.

\section{Simulation Studies}

Simulations were conducted to evaluate the performance of the proposed estimation algorithm for the driving load in several cases. Longitudinal dynamics of a vehicle are considered and the powertrain model used in this study includes relevant dynamic characteristics of the engine/transmission, and the driveline of the vehicle. The parameter values used are given in Table 1.

As shown in Fig. 6, many factors affect the magnitude of the driving load; for example, the vehicle speed, road grade, road condition, etc. Based on the analysis of the driving load resistance, simulation conditions to eval-

Table 1 Parameter values used in the vehicle model

\begin{tabular}{|c|c|c|c|}
\hline Specification & Variable & Value & Unit \\
\hline Mass of the Vehicle & $M$ & 1,250 & $\mathrm{Kg}$ \\
\hline $\begin{array}{c}\text { Mass Moment of } \\
\text { Inertia of the Vehicle }\end{array}$ & $I_{v}$ & 107 & $\mathrm{Kgm}^{2}$ \\
\hline Shaft Stiffness & $K_{s}$ & 6,742 & $\mathrm{Nm}$ \\
\hline $\begin{array}{c}\text { Aerodynamic Drag } \\
\text { Coefficient }\end{array}$ & $C_{a}$ & 0.2367 & $\mathrm{Kg} / \mathrm{m}$ \\
\hline Tire Radius & $r_{t}$ & 0.287 & $\mathrm{~m}$ \\
\hline
\end{tabular}

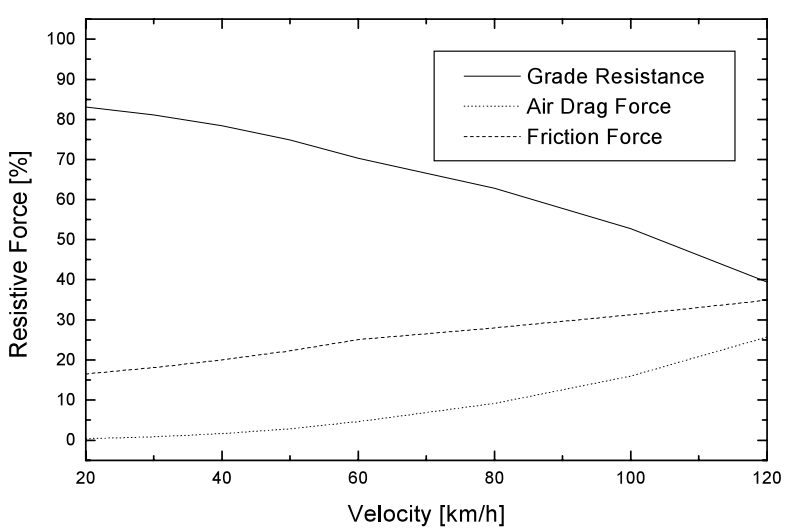

Fig. 6 Relative magnitudes of the driving resistive forces in terms of vehicle speed 

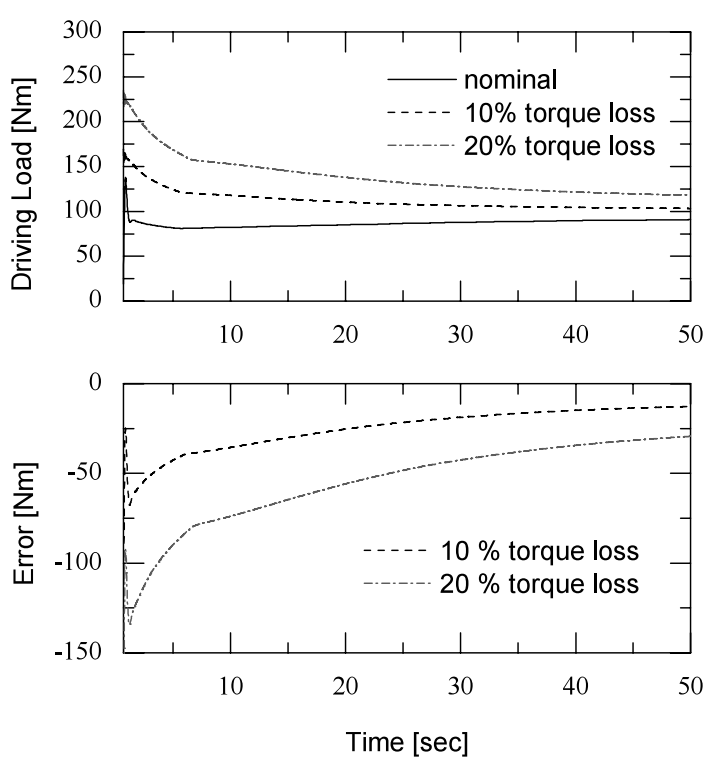

Fig. 7 Estimation performance under torque variations of power transmission: at $30 \%$ constant throttle operation

uate the performance of the proposed method are mainly divided into two parts; in the presence of a modeling error and in an uncertain environment of the running vehicle.

\subsection{In the presence of a modeling error}

Case 1: Variation in torque estimation

Figure 7 shows the simulation results for $10 \%$ and $20 \%$ torque losses. It shows that the torque losses caused by viscous drag torque in the torque converter and degraded performance of the engine can result in a large estimation error of the driving load. As illustrated in Fig. 4, the toque losses heavily depend on torque converter characteristic. The incorporation of the torque estimation technique using FNN model into the observer-based estimation algorithm of the driving load will reduce this estimation error caused due to torque losses.

Case 2: Parametric uncertainties

Nonlinearities and uncertainties in the parameters are involved in the vehicle system. So, the estimation method applied to vehicle control systems should be robust against those uncertainties. We perform simulations to evaluate the observer's ability to handle uncertainties, such as axle shaft stiffness. Figure 8 shows the estimation performance on running on a road slope under $30 \%$ uncertainty of axle shaft stiffness and the dynamic estimate of the observer is accurate even during transients.

\subsection{In an uncertain environment}

Case 1: Running on a road slope

As shown in Fig. 6, it is noted that grade resistance force dominates because an abrupt change in road slope contributes to a large variation of the driving load rather than the vehicle speed which is a slowly varying factor.

In Fig. 9, an uphill driving simulation test has been performed to evaluate the estimation capability on chang-
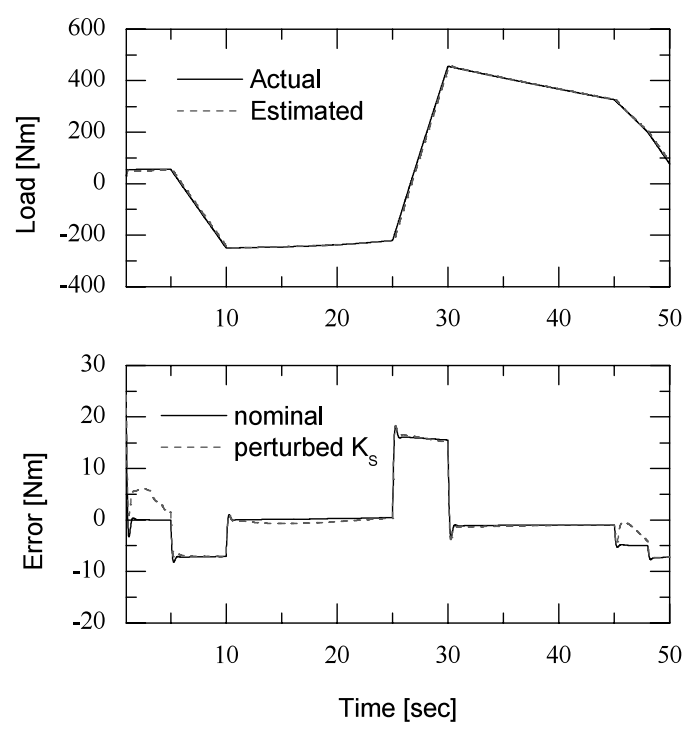

Fig. 8 Estimation performance with an uncertain parameter: $K_{s}$

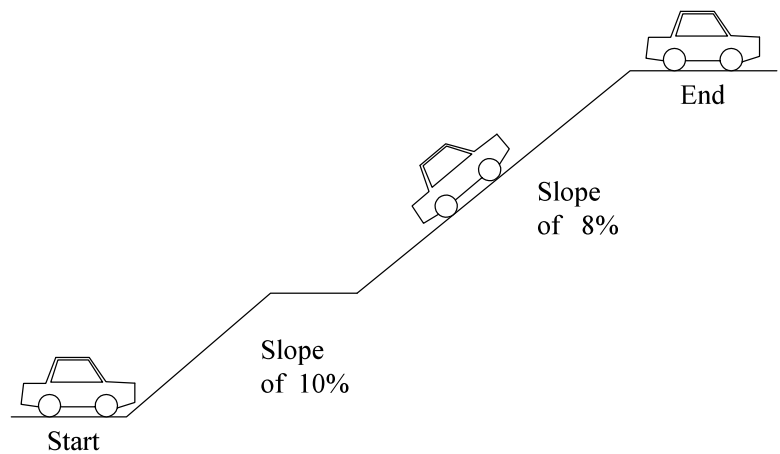

Fig. 9 Course condition for simulation
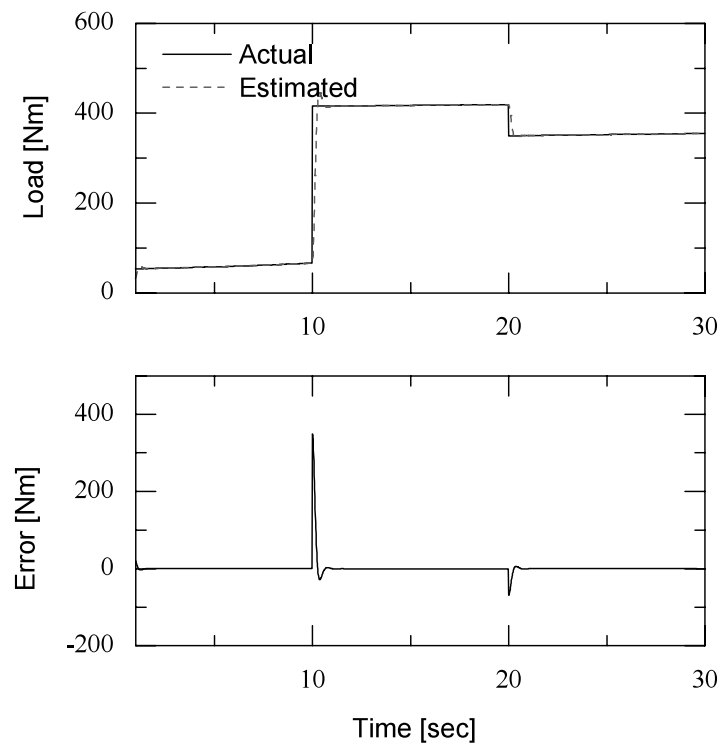

Fig. 10 Estimation performance on a varying road grade

ing course conditions. The driving load changes significantly with a step change in the road grade. Figure 10 shows that the proposed estimation scheme can provide 
Table 2 Coefficients of rolling resistance

\begin{tabular}{|c|c|c|c|}
\hline \multirow{2}{*}{ Tire type } & \multicolumn{3}{|c|}{ Surface } \\
\cline { 2 - 4 } & Concrete & $\begin{array}{c}\text { Medium } \\
\text { Hard Soil }\end{array}$ & Sand \\
\hline Passenger Car & 0.015 & 0.08 & 0.3 \\
\hline Truck & 0.01 & 0.06 & 0.25 \\
\hline Tractor & 0.02 & 0.04 & 0.2 \\
\hline
\end{tabular}
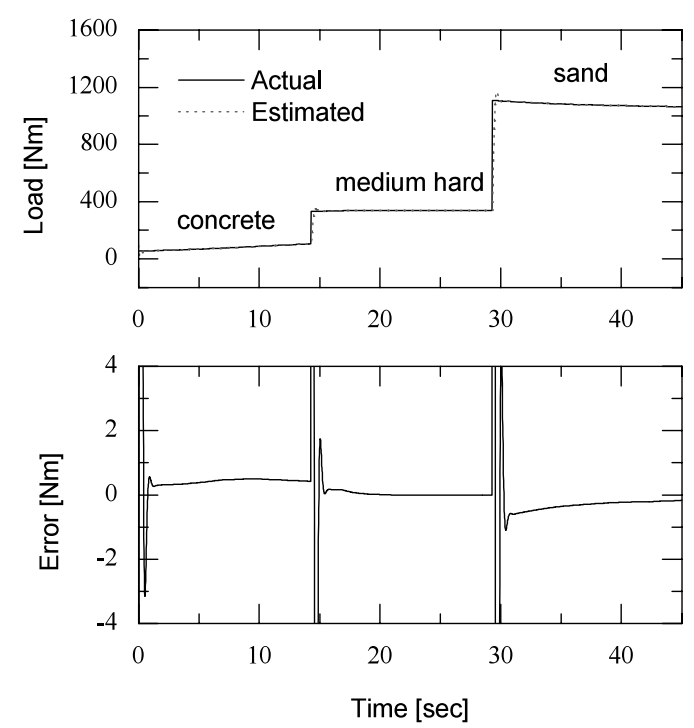

Fig. 11 Estimation performance under changes in road conditions

quite an accurate estimate even during abrupt changes in the road grade.

Case 2: Changes in road condition

The driving load varies widely with different road conditions: for example, concrete, medium hard, and sand. Coefficients of rolling resistance corresponding to different road conditions are shown in Table $2^{(23)}$. Figure 11 shows the estimation performance for abrupt changes in rolling resistance of a passenger car. The simulation results indicate that the driving load changes significantly with a change in the coefficient of rolling resistance due to different road conditions, and the observer shows good performance in accurately estimating the driving load for widely varying road conditions.

\section{Experimental Studies}

Experimental studies have been conducted to examine the proposed estimation method. Figure 12 shows a schematic diagram of the experimental setup. A photo of the experimental test setup is shown in Fig. 13. A torquecontrolled AC motor was used as an engine. An inertia load was used for the external driving load. The test setup includes all the sensors for measuring important variables in the powertrain system. The sensors for measuring angular speeds of the engine, turbine, and transmission out-

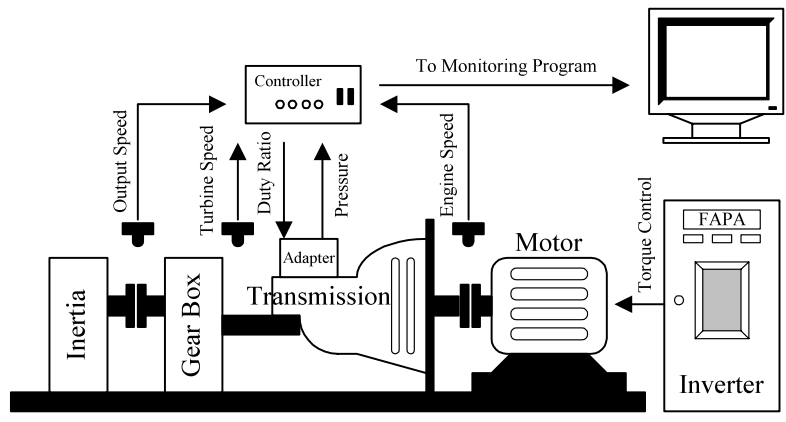

Fig. 12 Schematic diagram of the experimental test setup

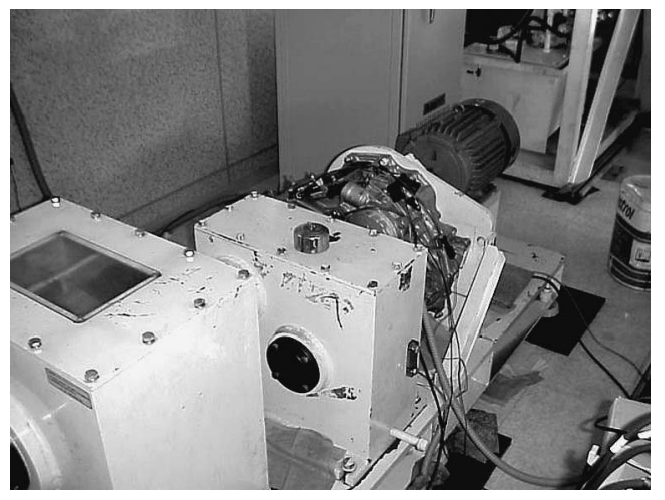

Fig. 13 The experimental test setup

put speed as well as a transmission fluid temperature sensor are equipped. A torque transducer has been installed in the transmission output shaft to measure the transmission output shaft torque, which is used for evaluating the performance of the turbine torque estimation by using the proposed estimation algorithm. The final implementation took the form of a look-up table, which was pre-evaluated with various conditions using a trained neural network model. The interpolation method was used in obtaining output values from given input values. The measurement of the engine speed, turbine speed, and oil temperature were done in every $10 \mathrm{msec}$.

Figure 14 shows experimental results of turbine torque estimation. In the case that the modeling error in torque is caused by the variation in torque converter characteristics, the estimation method using two static nonlinear curves may not be adequate and the estimation error is quite large at some operating conditions. The proposed estimation method shows a better agreement with experimental results compared with conventional method using static torque converter characteristics. Then, it has been incorporated in the driving load estimation algorithm using an observer for achieving better performance.

Figure 15 shows the estimation performance using the proposed algorithm when a step load torque is applied. Experiments were performed for uncertain changes in the driving load torque, which should cause degraded performance in vehicle control systems. The test condition is 


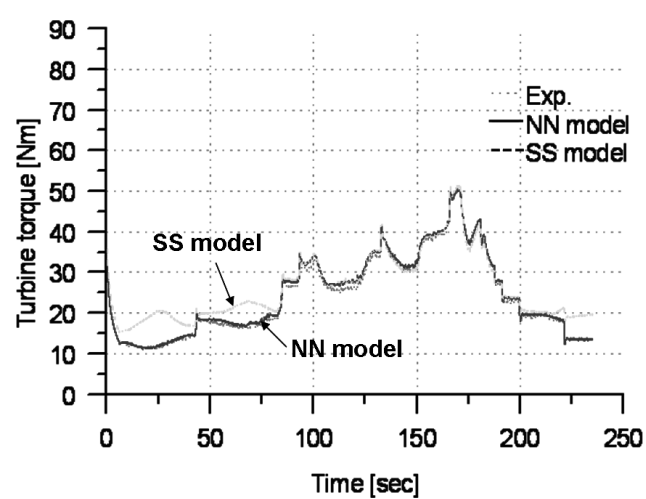

(a) Experimental results

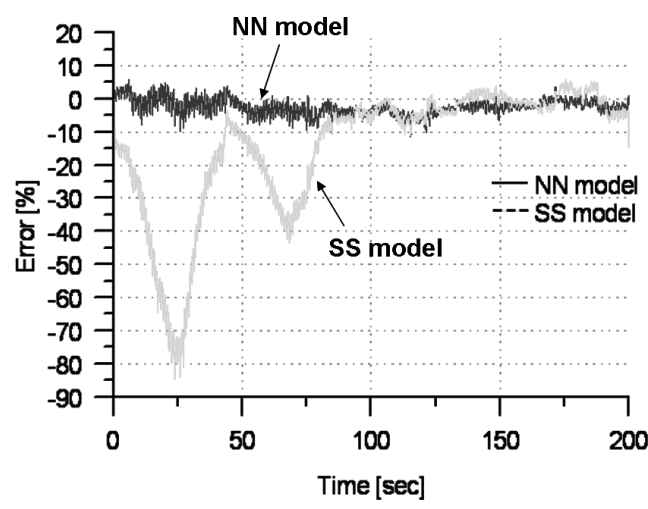

(b) Estimation error [\%] of the turbine torque

Fig. 14 Comparison of turbine torque estimations between the FNN model and the conventional model using static characteristic curve at $71-77^{\circ} \mathrm{C}$

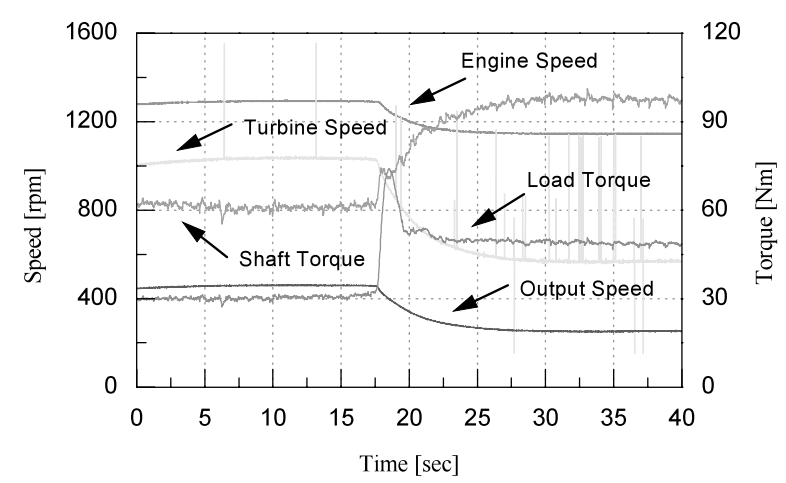

Fig. 15 Experimental result of driving load torque estimation

Table 3 Experimental test conditions

\begin{tabular}{|c|c|}
\hline Item & Condition \\
\hline ATF temperature & $70 \pm 5{ }^{\circ} \mathrm{C}$ \\
\hline Line pressure & $6.5 \pm 0.5 \mathrm{bar}$ \\
\hline Sampling frequency & $100 \mathrm{~Hz}$ \\
\hline Filtering & 3-pole LPF, $10 \mathrm{~Hz}$ cutoff \\
\hline
\end{tabular}

also shown in Table 3. The sampling time for the measurement and estimation is $10 \mathrm{~ms}$. The oil temperature is around the nominal condition (about $70^{\circ} \mathrm{C}$ ). As can be seen, it is noted that unexpected variations in driving load
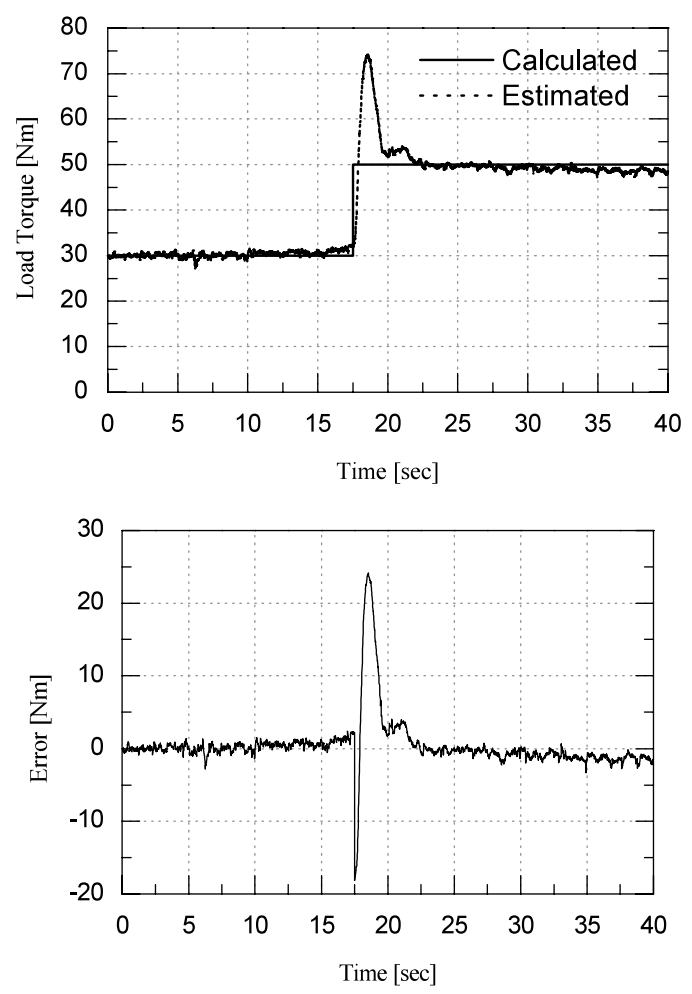

Fig. 16 Experimental result of driving load torque estimation

can be monitored by using the proposed driving load estimation method.

\section{Conclusions}

In this paper, an estimation scheme of the driving load in the form of an observer has been investigated. The developed scheme uses inexpensive rpm sensors currently being used in production vehicles. A new scheme for the estimation of the turbine torque, which is the input to the observer, has also been discussed. The effectiveness of the proposed method was demonstrated through the use of a full vehicle simulation model in various scenarios and vehicle dynamometer tests. The proposed estimation algorithm has good performance both over modeling error and in the uncertain environment. The estimated driving load can be effectively used in advanced longitudinal control systems such as an intelligent cruise control control, a CW/CA system, and a vehicle platoon control system.

\section{Acknowledgments}

The work was supported by the Ministry of Education and Human Resources Development, Korea, under a program of the Brain Korea 21 Project. The authors would like to thank Prof. Kyo-Il Lee at Seoul National University for his thoughtful guidance throughout their studies at their alma mater.

\section{References}

( 1 ) Liubakka, M.K., Rhode, D.S., Winkelman, J.R. and Kokotovic, P.V., Adaptive Automotive Speed Control, 
IEEE Transactions on Automatic Control, Vol.38, No.7 (1993), pp.1011-1020.

( 2 ) Rajamani, R., Tan, H.S., Law, B.K. and Zhang, W.B., Demonstration of Integrated Longitudinal and Lateral Control for the Operation of Automated Vehicles in Platoons, IEEE Transactions on Control Systems Technology, Vol.8, No.4 (2000), pp.695-708.

( 3 ) Rajamani, R. and Zhu, C., Semi-Autonomous Adaptive Cruise Control Systems, IEEE Transactions on Vehicular Technology, Vol.51, No.5 (2002), pp.1186-1192.

( 4 ) Yi, K.S., Woo, M.S., Kim, S.H. and Lee, S.C., A Study on Road-Adaptive CW/CA Algorithm for Automobiles Using HiL Simulations, JSME Int. J., Ser. C, Vol.42, No.1 (1999), pp.163-170.

( 5 ) Kim, Y.S. and Hong, K.S., An IMM Algorithm for Tracking Maneuvering Vehicles in an Adaptive Cruise Control Environment, International Journal of Control, Automation, and Systems, Vol.2, No.3 (2004), pp.310318.

( 6 ) Hayashi, K., Shimizu, Y., Dote, Y., Takayama, A. and Hirako, A., Neuro Fuzzy Transmission Control for Automobile with Variable Loads, IEEE Transactions on Control System Technology, Vol.3, No.1 (1995), pp.49-53.

( 7 ) Hong, K.S., Yang, K.J. and Lee, K.I., Object Oriented Modeling for Gasoline Engine and Automatic Transmission Systems, Computer Applications in Engineering Education, Vol.7, No.2 (1999), pp.107-119.

( 8 ) Jeong, H.S. and Lee, K.I., Shift Characteristics Analysis and Smooth Shift for an Automatic Power Transmission, KSME International Journal, Vol.14, No.5 (2000), pp.499-507.

( 9 ) Jo, H.S., Park, Y.I., Lee, J.M., Lee, H.D. and Sul, S.K., A Development of Advanced Shift Control Algorithm for Hybrid Vehicle with Automated Manual Transmission, International Journal of Vehicle Design, Vol.7, No.4 (2000), pp.281-298.

(10) Kim, D.H., Yang, K.J., Hahn, J.O., Hong, K.S. and Lee, K.I., Smooth Shift Control of Automatic Transmissions Using a Robust Adaptive Scheme with Intelligent Supervision, International Journal of Vehicle Design, Vol.32, No.3/4 (2003), pp.250-272.

(11) Ohnishi, H., Ishii, J., Kayano, M. and Katayama, H., A Study on Road Slope Estimation for Automatic Transmission Control, JSAE Review, Vol.21, No.2 (2000), pp.235-240.

(12) Wong, J.Y., Theory of Ground Vehicles, (1993), Wiley,
New York.

(13) Kim, C.S and Lee, C.O., Speed Control of an Overcentered Variable-Displacement Hydraulic Motor with a Load-Torque Observer, Control Engineering Practice, Vol.4, No.11 (1996), pp.1563-1570.

(14) Yi, K.S., Lee, S.J. and Lee, K.I., Estimation of Vehicle Driving-Load with Application to Vehicle Intelligent Cruise Control, KSME International Journal, Vol.15, No.6 (2001), pp.720-726.

(15) Kim, D.H., Shin, B.K., Yi, K.S. and Lee, K.I., Vehicle Driving Load Estimation for Longitudinal Motion Control, Proceedings of FISITA World Automotive Congress, Seoul, Korea, Paper No. F2000G348, (2000).

(16) Cho, D. and Hedrick, J.K., Automotive Powertrain Modeling for Control, ASME Journal of Dynamic Systems, Measurement, and Control, Vol.111, No.4 (1989), pp.568-576.

(17) Hong, K.S., Sohn, H.C. and Hedrick, J.K., Modified Skyhook Control of Semi-Active Suspensions: A New Model, Gain Scheduling, and Hardware-in-the-Loop Tuning, ASME Journal of Dynamic Systems, Measurement, and Control, Vol.124, No.1 (2002), pp.158-167.

(18) Yang, K.J., Hong, K.S. and Cho, D., A Robust Control for Engine and Transmission Systems: Enhancement of Shift Quality, JSME Int. J., Ser. C, Vol.44, No.3 (2001), pp.697-707.

(19) Masmoudi, R.A. and Hedrick, J.K., Estimation of Vehicle Shaft Torque Using Nonlinear Observers, ASME Journal of Dynamic Systems, Measurement and Control, Vol.114, No.4 (1992), pp.394-400.

(20) Yi, K.S., Shin, B.K. and Lee, K.I., Estimation of Turbine Torque of Automatic Transmissions Using Nonlinear Observers, ASME Journal of Dynamic Systems, Measurement, and Control, Vol.122 (2000), pp.276283.

(21) Meditch, J.S. and Hostetter, G.H., Observers for Systems with Unknown and Inaccessible Inputs, International Journal of Control, Vol.19, No.3 (1974), pp.473480.

(22) Kim, Y.K. and Jeon, G.J., Error Reduction of Sliding Mode Control Using Sigmoid-Type Nonlinear Interpolation in the Boundary Layer, International Journal of Control, Automation, and Systems, Vol.2, No.4 (2004), pp.523-529.

(23) The MathWorks, Inc., Using SIMULINK, (1997). 